CANADIAN JOURNAL OF

Disability Studies

Published by the Canadian Disability Studies Association · Association Canadienne des Études sur I'Incapacité

Canadian Journal of Disability Studies

Published by the Canadian Disability Studies Association

Association Canadienne des Études sur le handicap

Hosted by The University of Waterloo

www.cjds.uwaterloo 
Goodley et al., Rebooting Inclusive Education?

CJDS 9.5 (December 2020)

\title{
Rebooting Inclusive Education? New Technologies and Disabled People
}

\author{
Dan Goodley \\ iHuman, School of Education, University of Sheffield, England, UK \\ d.goodley@sheffield.ac.uk \\ David Cameron \\ iHuman, iSchool, University of Sheffield, England, UK \\ d.s.cameron@sheffield.ac.uk \\ Kirsty Liddiard \\ iHuman, School of Education, University of Sheffield, England, UK \\ k.liddiard@sheffield.ac.uk \\ Becky Parry \\ iHuman, School of Education, University of Sheffield, England, UK \\ r.1.parry@sheffield.ac.uk \\ Katherine Runswick-Cole \\ iHuman, School of Education, University of Sheffield, England, UK \\ k.runswick-cole@sheffield.ac.uk \\ Ben Whitburn \\ Research for Educational Impact (REDI) Faculty of Arts and Education, Deakin University \\ Melbourne Australia \\ b.whitburn@deakin.edu.au \\ Meng Ee Wong \\ National Institute of Education, Nanyang Technological University, Singapore \\ mengee.wong@nie.edu.sg
}

\begin{abstract}
This paper provides a speculative, conceptual and literature-based review of the relationship between disability and new technologies with a specific focus on inclusive education for disabled people. The first section critically explores disability and new technologies in a time of Industry 4.0. We lay out some concerns that we have, especially in relation to disabled people's peripheral positionality, when it comes to these new developments. The second section focuses on the area of inclusive education. Inclusion and education are oftentimes in conflict with one another. We tease out these conflicts and argue that we cannot decouple the promise of new technologies from the challenges of inclusive education, because, in spite of the potential for technological mediation to broaden access to education, there remains deep-rooted problems with exclusion. The third section of our paper explores affirmative possibilities in relation to the interactions between disability and new technologies. We draw on the theoretical fields of Science and Technology Studies; Critical Disability Studies; Assistive and Inclusive Technologies; Collaborative Robotics, Maker and DIY Cultures and identify a number of key considerations
\end{abstract}


Goodley et al., Rebooting Inclusive Education?

CJDS 9.5 (December 2020)

that relate directly to the revaluing of inclusive education. We conclude our paper by identifying what we view as pressing and immediate concerns for inclusive educators when considering the merging of disability and technology, accessibility and learning design.

\section{Keywords}

Critical Disability Studies, Assistive and Inclusive Technologies, Collaborative Robotics, Maker and DIY Cultures 


\section{Introduction}

This paper provides a speculative, conceptual and literature-based review of the relationship between disability and new technologies with a specific focus on inclusive education for disabled people. As researchers in the fields of disability studies, inclusive education, digital literacy and technology, spanning three continents, we are currently working together to contemplate the promise of new technologies. We have written this paper in order to identify some of the tensions and possibilities that arise when we intersect critical disability studies with studies of new technologies and inclusive education. The first section critically explores disability and new technologies in a time of Industry 4.0. While much is made of this fourth industrial revolution and the potentially empowering impact of new tech, we lay out some concerns that we have, especially in relation to disabled people's peripheral positionality when it comes to these new developments. We argue that any consideration of technological potential has to be understood in a wider context of disability exclusion. One should not automatically assume that Industry 4.0 is a benevolent context.

The second section focuses our analysis, somewhat, on the area of inclusive education, which we understand as the full participation of disabled people in education, throughout the life course, from early years, compulsory schooling into university education to vocational training and lifelong learning. Education and inclusion are oftentimes in conflict with one another. We tease out these conflicts and argue that we cannot decouple the promise of new technologies from the challenges of inclusive education, because, in spite of the potential for technological mediation to broaden access to education, exclusion is a daily reality for many disabled people.

The third section of our paper explores affirmative possibilities in relation to the interactions between disability and new technologies. We draw on the theoretical fields of Science and Technology Studies; Critical Disability Studies; Assistive and Inclusive 
Goodley et al., Rebooting Inclusive Education?

CJDS 9.5 (December 2020)

Technologies; Collaborative Robotics, Maker and DIY Cultures and identify a number of key considerations that relate directly to the revaluing of inclusive education. We conclude our paper by identifying what we view as pressing and immediate concerns for inclusive educators when considering the merging of disability and technology, accessibility and learning design.

\section{Section 1. The promise of new technologies}

New technologies are exponentially growing with the promise of boosting human capabilities, raising productivity and enhancing entrepreneurship. For sure, there will be winners and losers in this technological revolution, though the extent to which disabled people will benefit from this revolution remains unclear. We wonder whether or not disabled people are actively engaged as leading consultants, designers and co-producers of enabling new technologies. What does technology simultaneously give and take away? And, crucially, in a time when education has arguably never been more neoliberal-ableist in its design (a reality that we will return to in our paper), will new technologies sustain this ideological turn or provide possibilities for puncturing normative modes of educational practice? This paper will address these questions by critically interrogating technologies - including digital, robotic and assistive - to consider their potential to help tackle the educational exclusion and inclusion of disabled young people and their paths from compulsory schooling through to vocational and university education. We seek to consider how we might synthesise new technologies and disability as driving subjects of transformation. In particular, we are interested in the dynamic potential of new emerging technologies as tools for disability justice and social transformation (Goggin, 2018). 
Our conceptualisation of new technologies is expansive. These include established mainstream digital platforms and smart technologies (Google, Apple, Microsoft, IBM), cutting edge developments in robotics and manufacturing and specialist sensing (touch, eye, gesture, haptic, voice), augmentative, rehabilitative and dignity-enhancing technologies (Ellis, 2018: Goggin, 2018). We include DIY technologies supported by the Internet of Things (IoT) - the interconnection of the Internet with computing devices embedded in everyday objects — hacking and 3D printing (Hook et al., 2014). Our analysis, then, has potential relevance to an interdisciplinary community of researchers - from the computer, health, social and educational sciences - who are investigating the promise and pragmatics of new technologies in the lives of disabled people. There are, however, important questions to be asked about the rhetoric and hyperbolic claims made about new technologies, particularly as they relate to education. Facer (2019) suggests that the fields of anticipation and temporal studies raise helpful questions about the ways in which ideas about the future are used instrumentally to impact on what happens in the present. Dominant narratives surrounding the role of education and technology are strongly orientated to preparation of children for the future (Facer, 2019). Facer identifies three key narratives: firstly 'optimisation' - the idea that the future is knowable at least in the sense that technological innovation will continue to require a workforce including skills such as coding. The second narrative Facer characterises as 'colonisation', through which the future is presented as needing to be defined in ways that are deemed desirable, arising from particular political perspectives. Again there is an assumption that children must be equipped to bring this future into being. Finally, Facer identifies the 'contingency' narrative which she suggests is characterised by fear and doubt where the role of education is to be able to develop children who can cope with uncertainty. At the heart of her critique is a concern with the lack of opportunity to 
pay any sort of critical "attention to the richness of the meanwhile" and "collective encounters with the complexities of the present" (Facer, 2019, p. 12).

One aim of this paper is therefore to offer pause for thought; to question the aims and applications of these new technological developments: to bring the $\mathrm{D}$ (disability) into their Design. We refute technological determinism, which assumes that technology will necessarily and correctly dominate the development of social structures and cultural values, and, instead, ask; what does technology give to disability and, in turn, what does disability give to technology in the here and now?

\section{Disability troubles}

Just as new technologies grow exponentially so disability is ubiquitous. According to the 2011 World Report on Disability there are over one billion disabled people in the world (WHO \& The World Bank, 2011). This estimate has projected disability onto the world stage: as one of the major minority groupings across the globe and, in some senses, it has justified the work of critical disability studies scholarship. The argument goes that we should not need to give grounds for our work (which many of us often feel we have to do) when disability is so widespread (as evidenced by the World Report). However, recognition of this 'disability epidemic' is no benign act nor objective statement of fact. We know that the prominence of disability diagnoses — and therefore the growth in the sheer numbers of disabled people - is considered to be sapping the resources of governments and their institutions (Goodley, 2014; 2020). Disability tends to be framed as a problem. A big problem. And this trope constitutes disability in terms of human failing. Just as disabled people become ever-more recognised (in the classic administrative sense of being identified by nation states and supranational documents like the World Report) then 
Goodley et al., Rebooting Inclusive Education?

CJDS 9.5 (December 2020)

they also become constituted as problems (requiring a response; often in terms of cure and rehabilitation).

On the other side of the debate, social policies demand their citizens to be highly skilled and able in body and mind (Goodley, 2014; Mitchell \& Snyder, 2015). An example from Singapore: where the priority of Singapore's historical social welfare policy was not to place additional financial pressure on the state (Low \& Aw, 2004). Seeking to provide greater support for vulnerable populations continues to be guided strongly by meritocratic ideals which in turn can impose further structural and attitudinal barriers (Wong, in press). To this end, our current times are defined in terms of post-welfare and post-austerity societies. Key services, provisions and safety nets have been stripped away. Even in some high-income nations with traditions of strong social welfare — such as Iceland and Finland — support for disabled people has been drastically and dangerously reduced. Moreover, populism and isolationism—captured by Brexit and Trump - emphasise the independence and autonomy of nation states and their citizens (Goodley \& Lawthom, 2019). The self-sufficient individual is now a global given. And technological interventions are oftentimes associated with the augmentation of this self-serving global citizen.

We live in a contradictory contemporary moment; while human abilities are being technologically enhanced, this happens at a time when disability has never been so ever-present. Disability does not, of course, simply appear as a value-free phenomenon in the world. Disability comes at a cost. Disabled people consistently underperform in measures of health and wellbeing, educational achievement, labour participation and economic performance (WHO \& The World Bank, 2011). This precarity is exacerbated by austerity (Watkins et al., 2017). Of the 14 million disabled people in Britain, for example, many live in poverty, endure poor health, lack 
accessible housing and are marginalised in their communities (EHRC, 2018). Disabled people, then, are under siege. Their lives and life chances are significantly impacted upon by economic downturns and recession. Austerity threatens the very existence of disabled people. And, as austerity becomes the main philosophy of advanced neoliberal capitalist governments, then support for disabled people and their families is stripped away. In Britain, for example, the tortuous, prolonged and uncertain Brexit crisis plunged policy making into chaos. This could not have come at a worse time. The impacts of austerity have short and long tail effects. Some disabled people are now just feeling the reduction of key services and the withholding of much needed benefits. Others suffered at the very beginnings of austerity (Ryan, 2019). And as their lives become economically more troubling, the wider political climate in Britain does not help. Being disabled in Brexit Britain is a terrifying prospect. Any analysis, then, of the relationship between new technologies and disabled people has to keep in mind the human troubles faced by many disabled people.

\section{Industry 4.0}

We write this at a time when Schwab's (2016) conceptualisation of the Fourth Industrial revolution/Industry 4.0 enjoys global currency. This concept acknowledges the impact of rapid developments in new technologies on the performance of companies and employees. The volatile demands of the knowledge economy (Vercellone, 2007) have given rise to an era of cognitive capitalism where people's competences are mediated by technological progress (Rindermann \& Thompson, 2011, p. 754). This is the plugged-in-switched-on generation; a time where unadulterated, non-stop 24/7 working is, for many, the norm. In Britain, key funding bodies such as the United Kingdom Research and Innovation (2018, n.p.), conspicuously set out in their 
mission an Industry 4.0 attitude "to push the frontiers of human knowledge ... to become enriched, healthier, more resilient and sustainable.” British government research priorities include emerging classroom technologies; innovative pedagogies; differential participation in work and education (Department for Education [DoE], 2018; Department for Health [DoH], 2018; UKRI, 2018). And the Focused Research and Innovation Priority Areas of the Economic and Social Research Council's Delivery Plan 2019—-the main funder for social science research in Britain - include Productivity, Prosperity and Growth and Living with Technology (Economic and Social Research Council and UK Research and Innovation [ESRC \& UKRI], 2019). These missions and ambitions reflect, of course, the British government's Industrial Strategy to increase industry and public services productivity through the use of advanced technologies (Innovate UK and Department for Business, Energy \& Industrial Strategy [Innovate UK \& BEIS], 2017). Similarly, in Australia, continual innovation of new technologies to improve the ways that individuals interact with industries such as health and food have become national science and research priorities (Commonwealth of Australia, 2015).

New technologies are held up as a panacea for national productivity failings. And the promise of new technologies is part of everyday parlance. Got a problem? There's an App for that. Have a question? Google it. Failing at work, in school, in life, in relationships? Find 'an app for autism' and you'll be rewarded with 95,600,000 results in 0.6 seconds. Emerging new technologies bring with them many answers: though the quality, veracity and usefulness of those answers are questionable. We also wonder where this leaves disabled people: especially disabled young people in a culture that is increasingly individualistic, isolating and wrapped up in globally dominating discourses of meritocracy, self-sufficiency and self-governance. We wonder - and worry for that matter - about the marrying of economic productivity with matters 
Goodley et al., Rebooting Inclusive Education?

CJDS 9.5 (December 2020)

of disability justice and inclusion (Goggin, 2018; Pullin, 2009). Are these ambitions

complementary or in deep conflict with one another? Does Industry 4.0 have inclusive or exclusionary tendencies at its core?

\section{Section 2: Inclusive education}

Our analysis becomes somewhat more focused here on inclusive education: which we understand as the full participation of disabled people in education, throughout the life course, from early years, compulsory schooling into university education and vocational training and lifelong learning. The field of inclusive education has changed markedly over the last thirty years. In the UK, inclusive education enjoyed a purple patch in the late 1990s into the 2000s. This was due to the impact of pan-national movements such as Inclusion International, the potency of anti-racist, disablist and sexist campaigns, the impact of academic journals such as Disability \& Society and the International Journal of Inclusive Education as well as a plethora of practitioner, under and postgraduate courses across the world. Inclusive education in 2019 is, hardly surprisingly, a very different animal. In a recent text by a leading proponent of inclusive education, Roger Slee (2018) argues that inclusive education is not dead but smells funny. This playful title captures more profound and serious problems. We tease out three problems facing inclusive education from Slee's work.

The misappropriation of inclusive education: As with any phenomenon, especially one that emerges at the outset as a radical concept, there is always a problem of translation when this phenomenon is incorporated into different contexts across the world. Many practices sell themselves as inclusive education. This might include a special unit for disabled children attached to a mainstream school. Here children with Special Educational Needs (SEN) labels 
spend most of their time in the unit (particularly for lessons) and then mingle with other children during break times and lunch (if they're lucky). This co-location of special units is a preferred model in British schools. Following Slee (2018), however, we would not understand this as inclusion. If one goal of inclusion is to fundamentally radicalise the ways in which we organise our school systems then this model fails to change the normative ways in which schools function. The usual workings of the mainstream school continue. The unit functions in itself. Neither impinges on the other (Greenstein, 2014). Inclusive educators seek more; not least a cultural change to the workings of schools themselves to open up their practices in ways that increase a sense of belonging for all and facilitate equitable participation in teaching and learning.

A dominant culture of individualism works itself through all educational spaces and institutions. From Programme for International Student Assessment (PISA) scores that pitch national education systems against one another, to School League Tables that prompt families with high incomes to shop around for the best education for their children, through to the narrowing and standardisation of curricula and assessment measures, we have witnessed a rapid marketisation of education over the last thirty years. At the epicentre of these developments is the individual learner, student and pupil; the agent of educational progress. Individual progress is tied, unproblematically, to the progress of the educational institution and nation state: and the grades of the student act as a perfect marker of the success of the school and nation. Education, or at least mass education, across the capitalist world has always been tied to the constitution of productive learners who are ready, willing and able for work. And this individualisation of the very idea of education has been augmented by an individualisation of pedagogy, measurement and assessment. The consequences are clear; individual students, educational institutions, teachers, and educational managers flourish or fail by these performative measures. Inclusion 
becomes re-sited as a minority concern: a peripheral issue to engage with when the performative priorities of education have been met. At worse, inclusion is resisted; construed as a minority concern, a wishy-washy liberal idea that risks watering down the real business of education: the makings of the self-sufficient learner.

The illusion of special education. Just as 'Business as Usual' occurs in mainstream educational spaces then the power of special education has been rejuvenated. We agree with Slee (2018) that inclusive educators have failed to dismantle the power and promise of special education. And this illusion of special education — as the specialist and specialised knowledge through which SEN and disability can be properly managed — has gained a particular prominence in the contemporary moment. Special educational discourse has not been debunked by inclusive educators. In contrast, one could argue that special education has enjoyed a renaissance in thinking over the last three decades. We might cite the growing psychologisation of everyday life (De Vos, 2012) where the ideas, concepts, diagnoses, language and individualising preoccupations of psychological theory and science are used by societal members as if they were common-sense and everyday language. For example, the language of autism is just as commonplace in the cafe as it is the school and psychological knowledge has primed the strengthening of this vocabulary. Psychologisation creates the perfect breeding ground for certain kinds of knowledge and practice to reassert their authority. Special educational practitioners who work in the field of autism have had their expertise reinscribed at the same time as autism enjoys a growing mainstream prominence. Special education creates an illusion: setting itself off as distinct from the common-sensical and the everyday as the place where expertise might be found (in this case in relation to autism). 
Goodley et al., Rebooting Inclusive Education?

CJDS 9.5 (December 2020)

Inclusive education is, we would argue, on the ropes. It has been battered by the marketisation and neo-liberalisation of education. The values of inclusion hang by a thread. And this damning assessment of inclusion is one that we must keep with us when contemplating the intersections of disability and technology.

\section{Section 3: Theorising new technologies and disability as an opportunity to reboot inclusive education}

We strongly believe that there is a need to invigorate understandings of human ability, disability and technology through interdisciplinary dialogue. This is especially the case in relation to the philosophy and practice of inclusive education. In this third section of the paper, then, we seek some theoretical responses to the intersections of disability and technology. And, in so doing, we identify a number of key considerations that relate directly to the revaluing of inclusive education.

\section{Science and Technology Studies}

Science and Technology Studies (STS) has engaged critically with technological interventions including drugs and devices to extend physical and cognitive abilities; neuroscientific, epigenetic and biotechnologies associated with improving human performance and new techno-human, cyborg and posthuman identities (Braidotti, 2013; Carey, 2011; Coveney et al., 2011; Fukuyma, 2002; Gimlin, 2013; Haraway, 1991; Latour, 1988; Meloni \& Testa, 2014; Shonkoff \& Phillips, 2000). A number of STS researchers have approached technological enhancement as a socio-techno-organisational assemblage supplemented by other human entanglements, alliances and care (Fox \& Alldred, 2015). We share STS scholars' agnostic 
Goodley et al., Rebooting Inclusive Education?

CJDS 9.5 (December 2020)

attitude towards techno-enhancement and question the proposition that digital societies readily release human potential (Bostrom, 2005; Bostrom \& Sandberg, 2009; Persson \& Savulescu, 2012; Rose, 2007; Verlager, 2004; Wolbring, 2008). The 'Me Generation' of the 1970s and the 'Transhuman Generation' of the noughties illustrated how technological-human collaborations aid competition in the global marketplace (Bradbury \& Robert-Holmes, 2009; Fukuyama, 2004; Wolfe, 1976). But the STS literature suggests that only some sections of the population thrive in economic conditions emphasising responsibilisation and self-sufficiency (Campbell, 2009). Questions are raised about the extent to which disabled people can access cultural imaginaries associated with autonomy and self-governance just as powerful new technological interventions in biology, brain and behaviour reinvent what it means to be human (Clark, 2007; Hogle, 2005). And while digital worlds promote digital literacy from early childhood to older adulthood, marked global digital divides exist between rich/poor, global north/south, non/disabled people (Duplage, 2017; MacDonald \& Clayton, 2013; Marsh, 2016; Marsh et al., 2017). STS encourages us to consider:

- The reconstitution of social, economic and cultural divides between rich and poor nation states, economies, groups and individuals which will impact hugely upon the resources associated with inclusive education;

- The dangers of technological determinism which risk underplaying key human relations necessary for the workings of responsive forms of education;

- The growing influence of biosocial models of the human-emphasising neuroscientific, epigenetic and biotechnological perspectives - and their roll out into educational practices, pedagogies and policies; 
- The framing of the disabled child in terms of powerful and pernicious discourses of biosociality, psychologisation and psychiatrization.

\section{Critical Disability Studies}

We address an omission in the literature: understanding disabled people's participation in Industry 4.0. Drawing on Critical Disability Studies our view is that the capacities of disabled people can be strengthened through inclusive social, cultural, technological and material practices (Campbell, 2009; Goggin, 2018; Goodley, 2016; Mallett \& Runswick-Cole, 2014; Meekosha \& Shuttleworth, 2009; Roulstone, 1998; Shildrick, 2012). These might encompass participation in digital and social media alongside the positive consequences of universal and inclusive design (Boys, 2014; Goggin \& Newell, 2003, 2007; Hamraie, 2017; Jaeger, 2010; Lewthwaite, 2014; Pullin, 2009). Historically, disabled people have created interdependent forms of human/non-human connections including distributed competence, relational ethics, crip communities, feminist ethics of care, digital connectivity and human-animal-machine assemblages (Booth \& Booth, 1998; Feely, 2016; Kafer, 2013; Kittay, 2002; Mitchell \& Snyder, 2018; Reindall, 1999; Shakespeare, 2000; Shildrick, 2009; Trevisan, 2017; Whitney et al., 2019). These relational approaches capture disabled people's deep technological entanglements but also warn against technological determinism and normalisation (Morse, 2005; 2006). Our sense is that there is an urgent need to interrogate socio-techno-organisational relationalities by drawing on disability research that repositions disabled people as the inventors, makers and end-users of new technologies (Goggin, 2018; Holt \& Murray, 2019; Roulstone, 2016). We are drawn to the influence of Critical Posthumanities that blur the wetware of bodies with the hardware of machines (Bozalek, 2018; Braidotti, 2013, 2018; Braidotti \& Hlavajova, 2018; Braidotti \& 
Regan, 2017; Renold \& Ivinson, 2011). The posthuman citizen is a rich amalgamation of biology, technology and culture. Some people are afforded a central place and others a more peripheral position. Braidotti (2018) demands we address these disparities by being open to minoritarian knowledge which, following Muñoz (2005), works at the intersections of black, feminist, indigenous, queer, trans, disabled and displaced studies (Baynton, 2001; Wynter, 2003). We assert that there is a need to respond directly to this intersectional call; foregrounding disability and connecting with other identity positions associated with impairment, age, race, class, gender and sexuality. This leads us then to posit a number of key issues that need to be addressed including:

- The relative participation or absence of disabled people as designers, consultants and end-users of new technologies;

- The dangers of new technologies writing over already productive human-non-human relationships and assemblages historically developed and preferred by disabled people and their allies;

- The potential or problems of new technologies failing to engage with the expertise and politics of disabled people in developing responsive modes of inclusive education.

\section{Assistive and Inclusive Technologies}

We know from research in Assistive and Inclusive technologies—including Augmentative and Alternative Communication (AAC), Environmental Control and Dignity Enhancing Technologies - that new technologies can enable everyday lives of disabled people (Baxter et al., 2012; Hynan et al., 2015; O’Keefe et al., 2007). Disabled users control home devices (including TVs, lights, telephones, doors, curtains and windows) through technologies worked via speech or 
movement, communicated in absolute and digital communities. Alliances between rehabilitative, clinical and assistive engineers and technologists have joined up technological platforms (Cowan et al., 2015). Recent work has identified an urgent need to critically investigate the impact of assistive technologies on a range of end users with a variety of impairments; to simplify and democratise tech design; to explore the attitudes of people towards collaborative robots in the workplace; to address the lack of match between specialist assistive/mainstream technologies and to ensure disabled people participate in human enhancement debates (Autor, 2018; Grüber \& Rehmann-Sutter, 2014; Judge, 2018; Judge et al., 2015; Pawar et al., 2016; Ravneberg \& Soderstrom, 2017). Work in the area prompts a number of emerging issues and questions:

- The need to address empirical gaps by drawing in disabled people as experts-byexperience on the practical present and future aspirations of assistive and inclusive technologies in educational and vocational settings;

- The dangers of new emerging technologies developed by major global corporations overwriting or disconnecting from existing successful platforms and hardware of assistive technologies;

- A requirement to address the divide between those disabled people in rich/low income countries as well as disparities within nation states;

- The pressing need to bring together mainstream tech companies and specialist assistive technology developers to work on complementary systems.

\section{Collaborative Robotics}

Industry 4.0 has extraordinary impacts on the range and specialisms of human abilities (Deloitte, 2017; Goldin \& Katz, 2018). Two thirds of children in primary schools today will 
Goodley et al., Rebooting Inclusive Education?

CJDS 9.5 (December 2020)

work in jobs that currently do not exist (NESTA, 2017). Early adopters of new technologies will reap the greatest rewards in terms of additional jobs and increased revenue (BEIS, 2017). Data and digital technologies promise revolutionary transformational changes across the full range of industry sectors and spheres of life (Royal Society, 2017; Waterstone, 2018). Automation in Industry 4.0 may further unlock potential productivity, earnings, and demands for work (although how these gains may then be distributed within organisations remains an open question). And the emergence of collaborative robotics (or cobots) have the potential to enhance the impact of intelligent automation through bringing together the complementary abilities of humans and machines (Autor, 2015; Pawar et al., 2016). Well-considered and labour-centered introduction of collaborative robotics (e.g., through co-design and training workshops, Gwilt et al., 2018) may support the upskilling, rather than replacement, of present workers. However, certain sectors of the working age population—including women and disabled people — do not have the requisite skill-sets required of these rapidly developing industries to benefit from such developments (Waterstone, 2018). The parallel developments of advanced social robotics for educational uses may reshape the accessibility of learning environments. Such robots may be used not just as a medium for learning programming but as facilitators for students' inquiry (Belpaeme et al., 2018) or even as co-learners (Reidsma et al., 2016). How then might disabled people be drawn into rather than excluded by these developments? Too often collaborative robotics has a non-disabled user in mind. If, as predicted, robotics will increasingly enter all arenas of life - from the family home, to education, to work and leisure - then it is absolutely essential that disabled people are included as key stakeholders in these discussions and design. Our sense then is there an urgent need to explore: 
Goodley et al., Rebooting Inclusive Education?

CJDS 9.5 (December 2020)

- The ways in which disabled children and adults are centralised in debates and design of collaborative robots;

- The input of robotics in educational contexts and the place of robotics in curriculum and learning;

- The relationship between robotics R\&I and the research priorities of disabled people and their representative organisations.

\section{Maker and DIY Cultures}

Recent years have seen an explosion of interest in DIY and makerspace activities. These spaces integrate intellectual, pragmatic and activist concerns to democratise new technologies and re-associate cognitive ability and manual skills (Barba, 2015). Nascimento and Pólvora (2018, p. 930) state that "professional and amateur inventors, crafters, hackers, entrepreneurs, artists, scientists, engineers, designers, teachers, or activists modify, assemble, create, disassemble, recreate ... sharing objects and systems through open and collaborative networks from their homes, garages, schools, businesses, museums, libraries, makerspaces, hackerspaces." Makerspaces promote an ethics of DIY design — including digital fabrication and maker capacities (Blikstein, 2013; Doughty, 2012; Rose, 2014)—but many are inaccessible to disabled people (Brady et al., 2014). In contrast, there have been a number of events such as Haccessible Sheffield which have focused on the design ambitions of disabled co-designers and brought together computer scientists and mechanical engineers to work collaboratively in ways that utilise DIY ethics and practices to address a number of accessible technological ambitions. We would urge research and innovation associated with this work: 
- To promote inclusive and accessible makerspaces and identify DIY technologies that are crafted by disabled people in their roles as designers, consultants and users;

- Redefine the spaces of making and design in ways that invite designers with different kinds of embodiment and intellectual needs;

- Consider disability as the starting point from which to think more broadly about innovative prototypes, products and designs.

\section{Conclusions}

In this final section, we identify several ways forward for what we consider pressing and immediate concerns for educators and researchers alike when considering the merging of disability and technology, accessibility and learning design. This necessarily speaks across the above threads of discussion — STS, assistive and inclusive technologies, collaborative robotics and maker and DIY cultures—simultaneously with inclusive and participatory methodologies. While we are in no doubt that technology can support educators to create inclusive teaching and learning, disabled people are recurrently prevented from full participation in these activities. We might consider the role of technology to this end - the ways that technology has traditionally been designed as a therapeutic response to disability, but also, how its potential contribution is overhyped as a panacea to the democratisation of education (Selwyn, 2016). Like Selwyn (2016, p. 441), "the ways that digital technology is talked about within educational circles certainly extenuate superficial, ephemeral and often banal aspects of the topic at the expense of any sustained engagement with its messy politics."

Useful parallels can be drawn here with technology and disability studies, whereby until recently, critical perspectives have been in short supply (Gallis, 2011; Goggin, 2018; Moser, 
Goodley et al., Rebooting Inclusive Education?

CJDS 9.5 (December 2020)

2006). To this end, Goggin (2018, p. 83) advances an appeal to "rethink technology from

disability coordinates." In closing, we pursue this provocation while gesturing all the while at inclusive education.

Reimagining technology, disability and inclusion for different educational contexts we should be concerned with the ableist ways that technologies are framed in the constitution of both disability and inclusion in education across the sectors. We contend that any efforts to reposition digital technology away from a normativising 'device' depends upon the elaboration of alternative knowledge about its use, thereby influencing its design. We agree with Selwyn (2016, p. 442) who observes:

A more radical alternative would be to broker deliberately 'honest' declarations of the likely consequences of digital technology use... stimulating genuine public conversation about digital education amongst those who have direct and diverse lived experiences of it, [and] providing a counterpoint to what currently passes for public discourse on the topic. Though Selwyn's concerns are directed at the potential for technology to democratise education more generally over improving its inclusiveness of and for disabled students, the pertinence of his thesis is in his appeal to public engagement to develop knowledge about the utility of digital tools. Similarly, what we advocate for here is an orientation toward what Galis (2011) calls the ontological peculiarities of disability; borrowing from STS the coinciding concern for how disability is experienced, is constructed by socio-cultural imaginaries, practices and norms, is presupposed in policy and technological developments, and re-produced in architectural environments. This approach adopts an understanding that disability is made in different circumstances and the power relations that underpin certain technological practices can either enable or disable interactions (Moser, 2006). Across different educational contexts, we are 
invited to consider the affects that disability makes possible through the use of particular technological devices that disabled users use in relational assemblages with teachers, curriculum, peers, policy makers, technology producers, learning designers, and other concerned groups to propel equitable participation. This approach to research is as much concerned with the provision — and as well the pedagogies—of technologies as it is with design; with the ways interactions are made possible through the mobilisation of accessible technologies as the power relations that foreclose them.

An example might support this point: one of the authors (Ben) uses a popular screen reading package for Windows, in conjunction with a refreshable braille display, and an iPhone. These devices have been (and continue to be) indispensable to his capacity to communicate, study, navigate and to gain and retain employment for the ways they mediate accessibility to information, and as well to the mainstream applications used by millions across the world for word processing, email, and other tasks. It is recurrently taken as read at Ben's workplace that the mere provision of resources in electronic formats will ensure accessibility. Emailing, say, a copy of a pdf document, or a set of Powerpoint slides before a meeting, will be sufficient to ensure parity can be maintained. Yet, what continually goes unnoticed is that despite best intentions, social engagement with these provisions remain unequal. For instance, assuming these resources have been designed to be accessible (and they are invariably not), it is not often evident when a presenter transitions between slides, draws attention to particularities through highlighting texts on a screen, changes focus to video content, or other commonplace approaches to portraying information to an audience.

The subtext to this example worth deliberating, beyond the ocularcentric ways that continue to dominate knowing and being (Whitburn \& Michalko, 2020), is that accessibility, 
Goodley et al., Rebooting Inclusive Education?

CJDS 9.5 (December 2020)

though often easy to implement, is not assured when social convention fails to account for it.

Gabrielle Hodge (2017), a deaf linguist, has observed similar challenges to accessibility that places social and economic encumbrances upon disabled individuals. As she writes in relation to her PhD studies (Hodge, 2017, p. 162):

Much of postgraduate life occurs off-campus at conferences and workshops. When it comes to accessing these fundamental and thrilling events, I need support from Auslan interpreters or live English captioning. Both are expensive. But unlike buying a wheelchair or other assistive device, there is no tangible end product... I also need to spend money every time I want to use them.

Hodge's discussion illustrates challenges brought about through the combination of technological and social relations. To this end, she goes on to explain that participation in everyday educational events requires ongoing negotiation with organisers, teachers, and funding bodies in an attempt to safeguard accessibility. These exemplars underpin the bottom line of our argument: in spite of the advancement of technology that can and does support the lives of disabled users, social convention in education dictates that accessibility is of most concern to those who lack it. We agree with Goggin $(2018$, p. 87) when he writes that "critical work is crucial to opening up the shaping of new technology systems, values, and imaginaries." We understand this, principally, to turn to the relational context of technologies - technical, social, and otherwise - in the pursuit of furthering participation in education.

Any contemplation of new tech must place disability front and centre. Moreover, disability should be the guiding subject through which to critically evaluate the impact of new tech on people's lives. This means ensuring the research is co-produced with disabled people as 
Goodley et al., Rebooting Inclusive Education?

CJDS 9.5 (December 2020)

equal partners as well as ensuring that the theoretical contributions from critical disability studies are used as the key conceptual and analytical makers for any radical analysis of Industry 4.0 (Goodley, 2020; Mosco, 2017). We need to always attend to the possibilities of new technologies; but we also should remain critical of the ways in which inequalities might be reaffirmed and reconstituted in our digital lives. 
Goodley et al., Rebooting Inclusive Education?

CJDS 9.5 (December 2020)

\section{References}

Abbott, D. W. F. \& Carpenter, J. S. W., 2014, 'Wasting precious time': Young men with Duchenne muscular dystrophy negotiate the transition to adulthood. Disability \& Society, 29, 1192-1205.

Alper, M. (2018). Inclusive sensory ethnography: Studying new media and neurodiversity in everyday life. New Media \& Society, 20(10), 3560-3579.

Autor, D. (2015) Why are there still so many jobs? The history and future of workplace automation. Journal of Economic Perspectives, 29(3), 3-30.

Blikstein, P. (2013). Digital fabrication and 'making' in education: The democratization of invention. In J. Walter-Herrmann \& C. Büching (Eds), FabLab: Of machines, makers and inventors (pp.203-222). Transcript Publishers.

Barba, E. (2015). Cultural change in the Twenty-First Century shop class. Design Issues, 31(4), pp.79-90.

Baynton, D. (2001). Disability and the justification of inequality in American history. In P. Longmore \& L. Umansky (Eds.), The new disability history: American perspectives (pp. 33-57). New York University Press.

Baxter, S., Enderby, P., Evans, P., \& Judge, S. (2012). Interventions using high-technology communication devices: A state of the art review. Folia Phoniatr Logop, 64, 137-144. https://doi.org/10.1159/000338250

Belpaeme, T., Kennedy, J., Ramachandran, A., Scassellati, B., \& Tanaka, F. (2018). Social robots for education: A review. Science robotics, 3(21), eaat5954. 
Goodley et al., Rebooting Inclusive Education?

CJDS 9.5 (December 2020)

Brady, T., Salas, C., Nuriddin, A., Rodgers, W., \& Subramaniam, M. (2014) MakeAbility:

Creating accessible makerspace events in a public library, Public Library Quarterly, 33

(4), 330-347. https://doi.org/10.1080/01616846.2014.970425

Booth, T. \& Booth, W. (1998). Parenting under pressure. Open University Press.

Bostrom, N. (2005) A history of transhumanist thought. Journal of Evolution and Technology, 14(1), n.p.

Bostrom, N., \& Sandberg, A. (2009). Cognitive enhancement: Methods, ethics, regulatory challenges. Science and Engineering Ethics, 15(3), 311-341.

Boys, J. (2014). Doing disability differently: An alternative handbook on architecture, dis/ability and designing for everyday life. Routledge.

Bradbury, A. \& Roberts-Holmes, G. (2017). Grouping in the early years and key stage 1: A necessary evil? Final report. National Education Union.

https://neu.org.uk/media/3191/view

Braidotti, R. (2013). The posthuman. Polity.

Braidotti, R. (2018). A theoretical framework for the critical posthumanities. Theory, Culture \& Society, 36(6), 31-61. https://doi.org/10.1177/0263276418771486

Braidotti, R. \& Hlavajova, M. (2018). (Eds). Posthuman glossary. Bloomsbury.

Braidotti, R. \& Regan, L. (2017) Our times are always out of joint: Feminist relational ethics in and of the world today: An interview with Rosi Braidotti, Women: A Cultural Review, 28(3), 171-192.

Bozalek, V., Braidotti, R., Zembylas, M. \& Shefer, T. (Eds.). (2018), Socially just pedagogies: Posthumanist, feminist and materialist perspectives in higher education. Bloomsbury. 
Goodley et al., Rebooting Inclusive Education?

CJDS 9.5 (December 2020)

Campbell, F.K. (2009). Contours of ableism: The production of disability and abledness.

Palgrave Macmillan.

Carey, N. (2011) The epigenetics revolution: how modern biology is rewriting our understanding of genetics, disease and inheritance. Icon Books.

Clark, A. (2007). Re-inventing ourselves: The plasticity of embodiment, sensing, and mind. Journal of Medicine and Philosophy, 32(3), 263-282.

Commonwealth of Australia. (2015). Science and Research Priorities.

https://www.industry.gov.au/data-and-publications/science-and-research-priorities

Connell, J. \& Klem, A. (2000) You can get there from here: Using a theory of change approach to plan urban education reform. Journal of Educational and Psychological Consultation, 11(1), 93-120.

Coveney, C. M., Williams, S. J., \& Gabe. J. (2011). The sociology of cognitive enhancement: Medicalisation and beyond. Health Sociology Review, 20(4), 378-390.

Cowan, D., Cudd, P. and Judge, S. (2015) Over a decade of developing the assistive technology field in the UK. Technology and Disability, 27, 1-3.

Deloitte (2016). Talent for survival | Essential skills for humans working in the machine age. https://www2.deloitte.com/content/dam/Deloitte/uk/Documents/Growth/deloitte-uk-talentfor-survival-report.pdf

Department for Education. (2018). Areas of research interest: May 2018. Crown Copyright. Department for Health (2018). Areas of research interest: May 2018. Crown Copyright. Department for Business, Energy \& Industrial Strategy (2017). Industrial strategy: Building a Britain fit for the future. 
Goodley et al., Rebooting Inclusive Education?

CJDS 9.5 (December 2020)

https://www.timeshighereducation.com/sites/default/files/breaking_news_files/industrial$\underline{\text { strategy-white-paper.pdf }}$

Dicks, B., Soyinka, B., \& Coffey, A. (2006). Multimodal ethnography. Qualitative Research, 6(1), 77-96. https://doi.org/10.1177/1468794106058876

Dougherty, D. (2012). The maker movement. Innovations, 7(3), 11-14.

Duplaga, M. (2017) Digital divide among people with disabilities: Analysis of data from a nationwide study for determinants of Internet use and activities performed online. PLOS ONE 12(6), e0179825. https://doi.org/10.1371/journal.pone.0179825

Economic and Social Research Council and UK Research and Innovation (2019). Delivery plan. https://www.ukri.org/files/about/dps/esrc-dp-2019/

Ellis, K. (2018). A media manifesto. In K. Ellis, R. Garland-Thomson, M. Kent and R. Robertson. (Eds). Manifestos for the future of Critical Disability Studies. (pp. 92-107). Routledge.

Equality and Human Rights Commission / EHRC (2018). Is Britain fairer? The state of equality and human rights in 2018. https://www.equalityhumanrights.com/en/britain-fairer/britainfairer-2018-supporting-data

Fox, N. \& Alldred, P. (2015) New materialist social inquiry: designs, methods and the researchassemblage. International Journal of Social Research Methodology, 18(4), 399-414.

Feely, M. (2016). Disability studies after the ontological turn: A return to the material world and material bodies without a return to essentialism. Disability \& Society 31(7), 863-883.

Fukuyama, F. (2004, October 23). Transhumanism. Foreign Policy, 144(Sep-Oct), 42-43. https://foreignpolicy.com/2009/10/23/transhumanism/ 
Goodley et al., Rebooting Inclusive Education?

CJDS 9.5 (December 2020)

Fukuyama, F. (2002) Our posthuman future: Consequences of the biotechnology revolution. Profile.

Galis, V. (2011). Enacting disability: How can science and technology studies inform disability studies? Disability \& Society, 26(7), 825-838.

Gimlin, D. L. (2013) "Too good to be real”: The obviously augmented breast in women's narratives of cosmetic surgery. Gender and Society, 27(6), 913-934.

Goggin, G. (2018). Technology and social futures. In K. Ellis, R. Garland-Thomson, M. Kent \& R. Robertson (Eds.), Manifestos for the future of Critical Disability Studies (pp. 79-90). Routledge.

Goggin, G., \& Newell, C. (2003). Digital disability: The social construction of disability in new media. Rowman \& Littlefield.

Goggin, G., \& Newell, C. (2007). The business of digital disability. The Information Society, 24(2), 159-168.

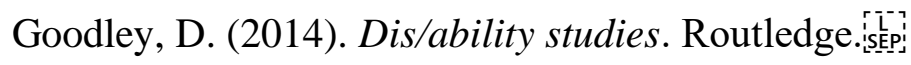

Goodley, D. (2016). Disability studies: An interdisciplinary introduction (2nd ed.). Sage Publishing.

Goodley, D. (2020). Disability and other human questions. Emerald Publishing Limited.

Goodley, D. \& Lawthom, R. (2019) Critical Disability Studies, Brexit and Trump: A time of neoliberal-ableism. Rethinking History, 23(2), 233-251.

Goldin, C. \& Katz, L. F. (2009) The race between education and technology. Harvard University Press

Greestein, A. (2014) Is this inclusion? Lessons from a very special unit, International Journal of Inclusive Education, 18(4), 379-391. 
Goodley et al., Rebooting Inclusive Education?

CJDS 9.5 (December 2020)

Grüber, K. \& Rehmann-Sutter, C. (2014) (Eds.). The human enhancement debate and disability: new bodies for a better life. Palgrave Macmillan.

Hamraie, A. (2017). Building access: universal design and the politics of disability. University of Minnesota Press.

Haraway, D.J. (1991). Simians, cyborgs and women: the reinvention of nature. FA Books

Hodge, G. C. E. (2017). Validating your access card: Striving beyond equality to equity (or something close enough). In C. McMaster, C. Murphy., B. Whitburn., \& I. Mewburn (Eds.), Postgraduate Study in Australia: Surviving and Succeeding (pp. 161-170). Peter Lang.

Hogle, L. (2005) Enhancement technologies and the body. Annual Review of Anthropology, 34, 695-716.

Holt, R. \& Murray, S. (2019). Prosthesis and the engineered imagination: Reading augmentation and disability across cultural theory, representation and product design. Medical Humanities, Epub ahead of print.

Hook, J., Verbaan, S., Durrant, A., Oliver, P., \& Wright, P. (2014, June 21-25). A study of the challenges related to DIY Assistive Technology in the context of children with disabilities. [DIS'14: Proceedings of the 2014 Conference on Designing Interactive Systems, pp. 597606]. ACM Conference on Designing Interactive Systems 2014, Association for Computing Machinery (ACM), New York.

Hynan, A. Goldbart, A. \& Murray, J. (2015). A grounded theory of Internet and social media use by young people who use augmentative and alternative communication (AAC). Disability and Rehabilitation, 37(17), 1559-1575. https://doi.org/10.3109/09638288.2015.1056387 
Goodley et al., Rebooting Inclusive Education?

CJDS 9.5 (December 2020)

Innovate UK and Department for Business, Energy \& Industrial Strategy (2017). Robotics and AI: Apply in the Industrial Strategy Challenge Fund. Crown Copyright.

Jaeger, P. T. (2010). Disability and the internet. Lynne Rienner.

Judge, S. Hawley, M. Cunningham, S. \& Kirton, A. (2015). What is the potential for context aware communication aids? Journal of Medical Engineering \& Technology, 39(7), 448453.

Judge, S. (2018). Assistive technology integration and accessibility. In L. Najafi \& D. Cowan (Eds.), Handbook of electronic assistive technology (1st ed.). Academic Press.

Kafer, A. (2013) Feminist queer crip. Indiana University Press.

Kittay, E. F. (2002). When caring is just and justice is caring: Justice and mental retardation. In Kittay, E. F. \& Feder, E. K. (Eds.), The subject of care: Feminist perspectives on dependency. Rowan and Littlefield Publishers.

Lewthwaite, S. (2014). Web accessibility standards and disability: Developing critical perspectives on accessibility. Disability and Rehabilitation, 36(16), 1375-1383.

Latour, B. (1988). Mixing humans and non-humans together: The sociology of a door-closer. Social Problems, 35, 298-310.

Liddiard, K., Runswick-Cole, K., Goodley, D., Whitney, S., Vogelmann, E. \& Watts, L. (2018) "I was excited by the idea of a project that focuses on those unasked questions": Coproducing disability research with disabled young people. Children and Society, 33(2). https://doi.org/10.1111/chso.12308

Macdonald, S. J. \& Clayton, J. (2013) Back to the future, disability and the digital divide. Disability \& Society, 28:5, 702-718. 
Goodley et al., Rebooting Inclusive Education?

CJDS 9.5 (December 2020)

Mallett, R. \& Runswick-Cole, K. (2014) Approaching disability: Critical issues and perspectives. Routledge

Marsh, J. A. (2016). The digital literacy skills and competences of children of pre-school age. Media Education: Studi, Ricerche, Buone Practice, 7(2), 197-214.

Marsh, J. A., Hannon, P., Lewis, M., \& Ritchie, L. (2017). Young children's initiation into family literacy practices in the digital age. Journal of Early Childhood Research, 15(1), 47-60.

Meekosha, H., \& Shuttleworth. R. (2009). What's so 'critical' about Critical Disability Studies? Australian Journal of Human Rights, 15 (1), 47-75.

Meloni, M. \& Testa, G. (2014). Scrutinizing the epigenetics revolution. BioSocieties, 9, 431456.

Mertens, D. M., Sullivan, M., \& Stace, H. (2011). Disability communities: Transformative research for social justice. In N. K. Denzin \& Y. S. Lincoln (Eds.), The Sage handbook of qualitative research (4th ed.) (pp. 227-241). Sage Publications.

Mitchell, D. T., \& Snyder, S. L. (2015). Biopolitics of disability: Neoliberalism, ablenationalism, and peripheral embodiment. University of Michigan Press.

Mosco, V. (2017). Becoming digital. Emerald Publishing Limited.

Moser, I. (2006). Disability and the promises of technology: Technology, subjectivity and embodiment within an order of the normal. Information, Communication \& Society, 9(3), 373-395.

Moser, I. (2005). On becoming disabled and articulating differences. Cultural Studies, 19(6), 667-700. 
Goodley et al., Rebooting Inclusive Education?

CJDS 9.5 (December 2020)

Muñoz, J.E. (2005) Teaching, Minoritarian knowledge, and love, Women \& Performance: A Journal of Feminist Theory, 14(2), 117-121.

Nascimento, S. \& Pólvora, A. (2018). Maker cultures and the prospects for technological action. Science and Engineering Ethics, 24, 927-946.

NESTA (2017). Employment in 2030: Skills, competencies and the implications for learning. https://www.nesta.org.uk/report/the-future-of-skills-employment-in-2030/

O’Keefe, B. M., Kozak, N. B., \& Schuller, R. (2007). Research priorities in augmentative and alternative communication as identified by people who use AAC and their facilitators. Augmentative and Alternative Communication, 23, 89-96.

Pawar, V. M., Law, J., \& Maple, C. (2016) Manufacturing robotics - The next robotic industrial revolution. UK-RAS Network: UK-RAS White Paper. https://www.ukras.org/wpcontent/uploads/2018/10/UK_RAS_wp_manufacturing_web.pdf

Persson, I. \& Savulescu, J. (2012) Unfit for the future? The need for moral enhancement. Oxford University Press.

Pullin, G. (2009). Design meets disability. MIT Press.

Ravneberg, B. \& Soderstrom, S. (2017). Disability, society and assistive technology. Routledge.

Runswick-Cole, K., Curran, T. \& Liddiard, K. (2017) A Handbook of disabled children's childhood studies. Palgrave MacMillan.

Reidsma, D., Charisi, V., Davison, D., Wijnen, F., van der Meij, J., Evers, V., Cameron, D., Fernando, S., Moore, R., Prescott, T., Mazzei, D., Pieroni, M., Cominelli, L., Garofalo, R., de Rossi, D., Vouloutsi, V., Zucca, R., Grechuta, K., Blancas, M., \& Verschura, P. (2016). The EASEL project: Towards educational human-robot symbiotic interaction. In Conference on Biomimetic and Biohybrid Systems (pp. 297-306). Springer. 
Goodley et al., Rebooting Inclusive Education?

CJDS 9.5 (December 2020)

Reindall, S. M. (1999). Independence, dependence, interdependence: Some reflections on the subject and personal autonomy. Disability \& Society, 14(3), 353-367.

Renold, E. \& Ivinson, G. (2014) Horse-girl assemblages: Towards a post-human cartography of girls' desire in an ex-mining valleys community, Discourse: Studies in the Cultural Politics of Education, 35(3), 361-376.

Rindermann, H., \& Thompson, J. (2011). Cognitive capitalism: The effect of cognitive ability on wealth, as mediated through scientific achievement and economic freedom. Psychological Science, 22(6), 754-763.

Rose, M. (2014). Not your father's shop class: Bridging the academic-vocational divide. American Educator, 38(3), 12-17.

Rose, N (2007) The politics of life itself: Biomedicine, power and subjectivity in the twenty-first century. Princeton University Press.

Roulstone, A. (1998). Enabling technology: Disabled people, work, and new technology. Open University Press.

Roulstone, A. (2016). Disability and technology: International and interdisciplinary perspectives. Palgrave.

Royal Society (2017). After the reboot-Computing education in UK Schools. https://royalsociety.org/ /media/policy/projects/computing-education/computingeducation-report.pdf

Ryan, F. (2019). Crippled: Austerity and the demonisation of disabled people. Verso.

Schadler, C. (2019). Enactments of a new materialist ethnography: Methodological framework and research processes. Qualitative Research, 19(2), 215-230.

Schwab, K. (2016). The fourth industrial revolution. World Economic Forum. 
Goodley et al., Rebooting Inclusive Education?

CJDS 9.5 (December 2020)

Selwyn, N. (2016). Minding our language: Why education and technology is full of bullshit... and what might be done about it. Learning, Media and Technology, 41(3), 437-443.

Sennett, R. (2009). The craftsman. Yale University Press.

Shakespeare, T. (2000) Help. Venture Press.

Shildrick, M. (2009). Dangerous discourses of disability, subjectivity and sexuality. Palgrave Macmillan.

Shildrick, M. (2012). Critical disability studies: Rethinking the conventions for the age of postmodernity. In N. Watson, A. Roulstone, \& C. Thomas (Eds). Routledge handbook of disability studies (pp. 30-41). Routledge.

Shonkoff, J. P., \& Phillips, D. (2000). From neurons to neighborhoods: The science of early childhood development. National Academy Press.

Slee, R. (2018). Inclusive education isn't dead, it just smells funny. Routledge.

Trevisan, F. (2017). Disability rights advocacy online: Voice, empowerment and global connectivity. Routledge.

UK Research and Innovation (2018). Strategic prospectus: Building the UKRI Strategy. Insight. Inspiration. Impact. Polaris House Swindon: UKRI.

Vercellone, C. (2007). From formal subsumption to general intellect: Elements for a Marxist reading of the theory of cognitive capitalism. Historical Materialism, 15(1), 13-36.

Verlager, A.K. (2004). Decloaking disability: Images of disability and technology in science fiction media [Unpublished B.A. English Masters dissertation]. University of Massachusetts, Boston. 
Goodley et al., Rebooting Inclusive Education?

CJDS 9.5 (December 2020)

Waterstone, R. (2018). Skills and education for robotics and AI (SERAI): A report for Sheffield Robotics. University of Sheffield.

https://serasorg.files.wordpress.com/2020/06/serai_final_report.pdf

Watkins, J., Wulaningsih, W., Da Zhou, C., Marshall, D., Sylianteng, C., Dela Rosa, P., Miguel, V., Raine, R., King, L., Maruthappu, M., (2018). Effects of health and social care spending constraints on mortality in England: A time trend analysis. BMJ Open, 7, e017722. doi:10.1136/ bmjopen-2017-017722

Wolbring, G. (2008). The politics of ableism. Development, 5(1), 252-258.

Wolfe, T. (1976, August 23). The "me" decade and the third great awakening. New York Magazine, n.p. https://nymag.com/news/features/45938/

Wong, M. E. (in press). The struggle for merit in meritocratic Singapore: Implications for persons with disabilities. In M. E. Wong \& L. Lim (Eds.), Special needs education: Trends and issues in Singapore. World Scientific.

World Health Organization and The World Bank. (2011). World report on disability. Geneva, Switzerland: World Health Organization. https://www.who.int/disabilities/world_report/2011/report.pdf

Wynter, S. (2003). Unsettling the coloniality of being/power/truth/freedom: Towards the human, after man, its overrepresentation-An argument. CR: The New Centennial Review, 3(3), 257-337.

Whitburn, B., \& R. Michalko. (2020). Blindness/sightedness: Disability studies and the defiance of di-vision.” In N. Watson \& S. Vehmas (Eds.), Routledge handbook of disability studies (2nd ed.). Routledge. 
Goodley et al., Rebooting Inclusive Education?

CJDS 9.5 (December 2020) 